\title{
Serviço Social, Questão Social e Políticas Sociais em tempos de degradação do trabalho humano, sob o domínio do capital financeiro.
}

\author{
Social Work, Social Issues and Social Policies in times of degradation of human work, under \\ the domain of financial capital
}

\section{Maria Carmelita Yazbek}

Este é tempo de partido, tempo de homens partidos. Carlos Drummond de Andrade

\section{Resumo:}

Este artigo objetiva analisar o Serviço Social brasileiro em suas orgânicas relações com a "Questão Socia $\left.\right|^{1 "}$ e a desigualdade fundante que a constitui no atual contexto de transformações estruturais e conjunturais que se processam sob a dominância do capital financeiro. Nessa direção, este texto privilegia a análise da profissão, frente às manifestações da questão social brasileira, questão que, nos contraditórios tempos presentes assume novas configurações e expressões que condensam múltiplas desigualdades mediadas por disparidades nas relações de gênero, características étnicoraciais, mobilidades espaciais, formações regionais e disputas ambientais, colocando em causa amplos segmentos da sociedade civil no acesso aos bens da civilização. Desse modo é fundamental não esquecer que o caráter predatório das relações coloniais e do escravismo deixou, sem dúvida suas marcas na história do país e implantou bases importantes na construção da lógica que vem presidindo a expansão do capitalismo dependente na periferia em tempos mais recentes, bem como as características próprias da Questão Social brasileira.

Palavras-Chave: Serviço social. Questão social. Políticas sociais. Capital financeiro.

\begin{abstract}
:
This article aims to analyze the Brazilian Social Service in its organic relations with the "Social Question" and the founding inequality that constitutes it, in the current context of structural and conjunctural transformations that occur under the dominance of financial capital is to face a very broad theme and complex. In this direction, this text privileges the analysis of the profession, in the face of the manifestations of the Brazilian social question, a question that in the present contradictory times assumes new configurations and expressions that "condense multiple inequalities mediated by disparities in gender relations, ethnic-racial characteristics, spatial, regional formations and environmental disputes, calling into question large segments of civil society in access to the

\footnotetext{
* Doutora em Serviço Social pela Pontifícia Universidade Católica de São Paulo. Pós-doutoramento no âmbito de ciências políticas pelo Instituto de Estudos Avançados da Universidade de São Paulo - USP. Professora do programa de Pós-Graduação em Serviço Social da Pontifícia Universidade Católica de São Paulo. Membro do Conselho Científico e Acadêmico da Faculdade de Serviço Social da UNLP - Argentina e professora visitante do Instituto Superior João Paulo II de Luanda Angola e da Universidade Lusófona do Porto.

1 A Questão Social é expressão das desigualdades sociais constitutivas do capitalismo. Suas diversas manifestações são indissociáveis das relações entre as classes sociais que estruturam esse sistema e nesse sentido a Questão Social se expressa também na resistência e na disputa política.
} 
goods of civilization. In this way, it is important not to forget that the predatory character of colonial relations and enslavement has undoubtedly left its mark on the history of the country and has established important bases in the construction of the logic that has been presiding over the expansion of dependent capitalism in the periphery in recent times, as the characteristics of the Brazilian Social Question.assumes new configurations and expressions that "condense multiple inequalities mediated by disparities in gender relations, ethnic-racial characteristics, spatial, regional formations and environmental disputes, calling into question large segments of civil society in access to the goods of civilization. In this way, it is important not to forget that the predatory character of colonial relations and enslavement has undoubtedly left its mark on the history of the country and has established important bases in the construction of the logic that has been presiding over the expansion of dependent capitalism in the periphery in recent times, as the characteristics of the Brazilian Social Question.

Keywords: Social work. Social issues. Social policies. Financial capital.

\section{Introdução}

Analisar o Serviço Social brasileiro em suas orgânicas relações com a "Questão Social" e a desigualdade fundante que a constitui, no atual contexto de transformações estruturais e conjunturais que se processam sob a dominância do capital financeiro é enfrentar uma temática bastante ampla e complexa, que nos coloca especialmente frente à "uma nova era de devastação, uma espécie de fase ainda mais destrutiva da barbárie neoliberal e financista que almeja a completa corrosão dos direitos do trabalho em escala global." (ANTUNES, 2018, p. 10).

Assim sendo, cabe inicialmente trazer ao debate a Questão Social nestes tempos de transformações da ordem capitalista, com seus impactos no mundo do trabalho e na ampliação das desigualdades. Hoje, 800 milhões de pessoas passam fome no planeta, enquanto a concentração de renda e de riqueza alcança

[...] níveis absolutamente obscenos [...] pois desde 2015, o $1 \%$ mais rico detinha mais riqueza que o resto do planeta. Atualmente, oito indivíduos detém a mesma riqueza que a metade mais pobre do mundo [...]. Esta concentração não se deve apenas à especulação financeira, mas sua contribuição é dominante (DOWBOR, 2017, p. 28-29).

Como se sabe, a desigualdade e a concentração de renda que se intensificam nas atuais formas de acumulação capitalista, resultam de mudanças na esfera da produção, associadas à nova hegemonia liberal-financeira e trazem como consequência a radicalização da questão social. No Brasil, chega-se assim, em 2018, a 14.830 milhões de brasileiros em situação de pobreza extrema (aumento de 11,2\% em relação ao índice de 2016). O número de trabalhadores informais superou o conjunto de empregados formais. A redução no 
número de beneficiários do Programa Bolsa Família no último ano, também foi apontada como um dos principais motivos para o aumento da pobreza e da desigualdade que permeiam a vida das "classes que vivem do trabalho" (cf. ANTUNES, 1999) na sociedade e com as quais defronta-se cotidianamente no trabalho profissional.

Nessa direção, este texto privilegia a análise da profissão, frente às manifestações da questão social brasileira, questão que, nos contraditórios tempos presentes assume novas configurações e expressões que,

[...] condensam múltiplas desigualdades mediadas por disparidades nas relações de gênero, características étnico-raciais, mobilidades espaciais, formações regionais e disputas ambientais, colocando em causa amplos segmentos da sociedade civil no acesso aos bens da civilização. Dispondo de uma dimensão estrutural - enraizada na produção social contraposta a apropriação privada do trabalho -, a 'questão social' atinge visceralmente a vida dos sujeitos numa luta aberta e surda pela cidadania, no embate pelo respeito aos direitos civis, sociais e políticos e aos direitos humanos (IAMAMOTO, 2018, p. 72).

Cabe lembrar ainda, que uma análise crítica da "Questão Social" no tempo presente exige que sejam considerados os processos de formação do país, desde a colonização, um empreendimento mercantil, que vai caminhar na direção de uma economia composta de senhores e escravos, na qual as marcas do patrimonialismo-paternalista vão plasmar a sociedade brasileira. "O par senhor-escravo assentou as bases de uma estrutura social bipolar, que formou a maior parte da nação. A casa grande e a senzala são o brasão dessa sociedade" (OLIVEIRA, 2018, p. 29).

Desse modo é fundamental não esquecer que o caráter predatório das relações coloniais e do escravismo deixou, sem dúvida suas marcas na história do país e implantou bases importantes na construção da lógica que vem presidindo a expansão do capitalismo dependente na periferia em tempos mais recentes, bem como as características próprias da Questão Social brasileira.

\section{Questão Social no Capitalismo Financeirizado e Políticas Sociais}

Infere-se que, pelo debate acumulado no âmbito do Serviço Social que a Questão Social e a desigualdade são elementos estruturantes da sociabilidade capitalista. Questão que se reformula e se redefine, mas permanece substantivamente a mesma por se tratar de uma questão estrutural, constitutiva das relações capitalistas, de sua divisão da sociedade em classes e da disputa pela riqueza socialmente construída, cuja apropriação é 
profundamente desigual no capitalismo. Supõe a consciência dessa desigualdade e a resistência à opressão por parte da "classe que vive do trabalho" (cf. YAZBEK, 2001).

No atual contexto, em especial nas últimas décadas o capital financeiro assumiu o comando no processo de acumulação de,

[...] forma que o campo de sua acumulação não mais apresenta fronteiras de qualquer ordem. [...] É um volume colossal de capital, na forma de títulos, ações e derivativos, que tem 'vida própria', altamente autonomizado dos processos produtivos e sua comercialização (MARQUES, 2018, p. 110-113).

A centralidade do capital financeiro e seu domínio sobre o capital produtivo traz consequências graves para a "classe que vive do trabalho" com a manutenção de taxas elevadas de desemprego, insegurança e instabilidade nos empregos, crescimento do trabalho informal e precário, redução de salários, precarização das relações de trabalho, incluindo terceirizações e contratos por prazos determinados, entre outros aspectos.

Este quadro, vem implicando numa ruptura do histórico pacto entre capital e trabalho que configurou no mundo desenvolvido, o Estado de Bem-Estar Social e na periferia do capitalismo algumas melhorias nas políticas sociais. Nesse sentido, a natureza desse capital precisa ser desvelada para entender o seu ataque contra as políticas sociais em relação às quais a conclusão que se chega é que não interessa a esse "capital manter políticas sociais organizadas e financiadas pelo Estado" (MARQUES, 2018, p. 110). Desse modo entende-se que o avanço do capital sobre as políticas sociais é uma característica do capitalismo contemporâneo globalmente, como anunciava Marques: "Nesse quadro, o lugar das políticas sociais está em um 'Não Lugar', pois não faz parte da agenda desse tipo de capital." (2015 apud MARQUES, 2018, p. 18). Característica que, aliada ao novo padrão de acumulação caracterizado pela flexibilização produtiva, com sua nova morfologia do mundo do trabalho com desemprego, redução de salários e precarização do trabalho e ausência de direitos, tem como resultado a ampliação de situações de trabalho desprotegido, o aumento da pobreza e o desmonte da proteção social.

No caso brasileiro, agrava-se a situação se for levado em consideração as particulares condições do desenvolvimento desigual e combinado do capitalismo no país. Traço da formação social brasileira, a conjugação do "avanço" com o "atraso" assegurou o sucesso da dominação burguesa desde sempre, apesar do período de conciliação de classes e de enfrentamento à pobreza, representado pelos governos de Lula e Dilma, com sua forma 
de investimento no social, denominada por alguns autores de neodesenvolvimentismo, expressa especialmente nos PTRC, no aumento do salário mínimo e nas Políticas Sociais com destaque para a Assistência Social. Contexto que se caracterizou pela combinação de "medidas de natureza oposta", e a articulação de dubiedades que permearam a política social brasileira. De um lado observou-se as tendências a focalizar e privatizar e de outro a perspectiva de construção de direitos garantidos constitucionalmente.

Assim, se está diante de uma sociedade "desigualitária sem remissão" como lembra Chico de Oliveira (2003, p. 146) onde a presença dos "pobres" no tratamento dos conflitos classistas tem sido uma constante.

De modo geral, na Política Social brasileira a luta contra a pobreza tomou o lugar da luta de classes. Trata-se de "ativar" trabalhos precarizados, intensificados e superexplorados. Para Singer (2018, p. 21) o "traço peculiar desta sociedade é o limbo, do qual os pobres podem sair (e no qual podem voltar a cair) individualmente, mas nunca como classe."

A perspectiva é de desenvolvimento dos "ativos" dos pobres, desconsiderando os fatores estruturais da pobreza, atribuindo a responsabilidade da pobreza aos próprios pobres. "Desvinculando a pobreza de seus determinantes estruturais, separam-se os indivíduos submetidos a essa condição de seus lugares no sistema produtivo (cf. LAUTIER, 1999 apud IVO, 2006, p. 69).

Assim sendo, observa-se que as classes trabalhadoras, mesmo ampliando a radicalização de sua exploração transformam-se nos pobres no âmbito das Políticas Sociais. É fundamental destacar que do ponto de vista da Política Social essa concepção hegemônica face às desigualdades econômicas sociais globais desconsidera "as razões e os mecanismos estruturais mais profundos, que (re)produzem as desigualdades." (FILGUEIRAS; GONÇALVES, 2009, p. 107). E, dessa forma, como por exemplo, no caso latino americano e brasileiro, são deixadas de lado as "estruturas concentradas de propriedade e poder" que caracterizam particularmente as periferias do capitalismo.

Essa postura, que vem orientando as políticas sociais no Continente, contribui para estabelecer o risco de limitar a reflexão e a intervenção social, incluindo aí o trabalho dos assistentes sociais a melhorias imediatas de condições de vida dos pobres, servindo tão somente para manter e controlar a pobreza e potencializar a legitimação do Estado. Cria-se um estrato de pobres que se reproduz no nível da sobrevivência, sendo instituída a ilusão de que o problema da pobreza será resolvido pela Política Social. 
O bem-estar social, direito inalienável de todo cidadão, sustentável, coletivo e universal, é colocado sob a responsabilidade dos indivíduos e das famílias, recaindo principalmente sobre a mulher a obrigação de administrar a família com valores monetários insuficientes para aquisição da cesta básica.

Do ponto de vista político, no país, no momento em que a acumulação e as manifestações de sua crise exigem novas formas políticas de gestão do Estado Burguês, as políticas sociais, que poderiam minimizar a pobreza, sob o impacto do golpe parlamentar, jurídico e midiático que depôs a presidente democraticamente eleita, passam a ser alvo de processos de desmanches. E desse modo, observa-se a um ataque sem precedentes às políticas de Seguridade Social, mais uma estratégia do capital para avançar sobre o Fundo Público. Por outro lado, depara-se nesse tempo com "contradições oriundas da ampliação da demanda por serviços e benefícios da assistência social num contexto de aprofundamento do desemprego estrutural, de precarização do trabalho e de insegurança social face à redução das proteções sociais do trabalho decorrentes da sua nova morfologia, expressas pela tríade flexibilização, informalização e terceirização do trabalho (cf. ANTUNES, 2013).

Politicamente, "As nossas classes dominantes sempre oscilaram no controle do poder político e da dominação no Brasil, oscilando entre a conciliação e o golpe, a conciliação e o desenho autocrático, a conciliação e a devastação" (ANTUNES, 2018, p. 53). Agora para o autor é o momento da devastação. É um rearranjo das classes dominantes, para prevenirem-se contra qualquer perda maior dessa crise em relação aos seus interesses, o que implica em desmontar a legislação social e laboral. Essa é a questão fundamental.

\section{Serviço Social e Questão Social no Capitalismo Financeiro}

Apoiada em lamamoto e Carvalho (1995) parto da posição de que a profissão e o conhecimento que a ilumina, se explicam no movimento histórico da sociedade e assim sendo, seu significado social só pode ser desvendado em sua inserção na sociedade, ou seja, a análise do Serviço Social, de suas demandas, tarefas e atribuições em si mesmas não permitem desvendar a lógica no interior da qual essas demandas, tarefas e atribuições ganham sentido. Assim sendo, é preciso ultrapassar a análise do Serviço Social em si mesmo para situá-lo no contexto de relações mais amplas que constituem a sociedade capitalista, particularmente, no âmbito das respostas que esta sociedade e o Estado constroem, frente à questão social e às suas manifestações, em múltiplas dimensões. Essas dimensões 
constituem a sociabilidade humana e estão presentes no cotidiano da prática profissional, condicionando-a e atribuindo-Ihe características particulares.

A partir dessa interlocução, no contexto de crise estrutural do capital com suas graves consequências para todos os domínios da vida social, econômica e cultural é que situa-se o Serviço Social brasileiro e seu processo de crescente legitimação no conjunto de mecanismos reguladores da Questão Social, no âmbito das políticas sociais, desenvolvendo sua intervenção e cumprindo objetivos que lhe são atribuídos socialmente e que, como se conhece, ultrapassam sua vontade e intencionalidade. Ou seja, o assistente social não tem se configurado como profissional autônomo no exercício de suas atividades, não dispondo do controle das condições materiais, organizacionais e técnicas para o desempenho de seu trabalho. No entanto, isso não significa que a profissão não disponha de relativa autonomia e de uma direção social que aponta para a construção de outra ordem societária.

Como se sabe, nas últimas três décadas o Serviço Social brasileiro construiu coletivamente um projeto para a profissão, forjado nas lutas dos movimentos sociais e articulado a um projeto societário anticapitalista. Esse projeto significou uma ruptura com o pensamento conservador que marcou a origem da profissão, sob influência do pensamento social da Igreja e de teorias de cariz positivista e funcionalista. Foi construído à luz do pensamento de autores marxistas e fundamentalmente a partir da Teoria Social de Marx e de suas explicações mais abrangentes e totalizantes acerca da vida social e de seu sentido histórico. Esse projeto trouxe importante inflexão na interpretação teórica da profissão, especialmente com a contribuição de Marilda lamamoto $(1995,2011)$ que traz a análise inaugural do Serviço Social como profissão no processo de produção e reprodução das relações sociais e capitalistas, particularizando sua inserção na divisão social e técnica do trabalho e reconhecendo o assistente social como trabalhador assalariado (YAZBEK, 2017a, p. 102).

Cabe lembrar que nessa perspectiva, a reprodução das relações sociais é entendida como a reprodução da totalidade da vida social, o que engloba não apenas a reprodução da vida material e do modo de produção, mas também a reprodução espiritual da sociedade e das formas de consciência social através das quais o homem se posiciona na vida social. Dessa forma, é preciso não esquecer, a reprodução das relações sociais é a reprodução de determinado modo de vida, do cotidiano, de valores, de práticas culturais e políticas e do modo como se produzem as ideias nessa sociedade. $\mathrm{O}$ processo de reprodução da totalidade das relações sociais na sociedade é um processo complexo, que contém a possibilidade do 
novo, do diverso, do contraditório, da mudança. Trata-se, pois, de uma totalidade em permanente reelaboração, na qual o mesmo movimento que cria as condições para a reprodução da sociedade de classes cria e recria os conflitos resultantes dessa relação e as possibilidades de sua superação (cf. YAZBEK, 2017a).

Nesse quadro de referências é fundamental ter presente que:

“Não há espaços sem contradição, não há como o Serviço Social deixar de participar desse processo, cuja direção está sempre em disputa, pois fazemos parte dela em qualquer contexto" (YAZBEK, 2017a, p. 101).

A partir desta abordagem e do intenso impacto que traz para a ruptura da profissão com o legado conservador de sua origem, situa-se o serviço social no âmbito do trabalho social coletivo,

[...] o que supõe a análise articulada do trabalho de assistentes sociais em sua dupla dimensão: de um lado, como trabalho concreto, é expressão do valor de uso dotado de qualidade específica que atende a necessidades sociais a partir de suportes intelectuais e materiais para sua realização [...] De outro lado, como trabalho abstrato - expressão do valor de troca abstraído de sua qualidade,representa uma fração do trabalho social total pensado em sua quantidade, como dispêndio de força humana de trabalho (RAICHELIS, 2018a, p. 156).

O Serviço Social, portanto, é parte integrante do processo histórico que assume as relações sociais na sociedade burguesa em seus processos de mudanças, inserindo-se no conjunto da classe trabalhadora, de suas lutas e apontando para a necessidade de um trabalho social orientado para a emancipação humana. Efetivamente, os assistentes sociais fazem parte da mudança, como gestores e operadores de políticas sociais, que se tem constituído historicamente numa das mediações fundamentais para o exercício profissional.

Assim, a profissão está envolvida diretamente com a construção cotidiana da sociabilidade capitalista pela mediação dessas políticas, operando dentro de seus limites e de suas possibilidades. Neste âmbito, desenvolve tanto atividades na abordagem direta com a população que procura as instituições e o trabalho do profissional (entrevistas, atendimento de plantão social, visita domiciliar, orientações, encaminhamentos, reuniões, trabalho com indivíduos, famílias, grupos, comunidades, ações de educação e organização popular etc.), assim como atua na pesquisa e na produção de conhecimento, administração, planejamento, supervisão, consultoria e gestão dessas políticas, programas e projetos na área social. 
Se essas políticas sofrem hoje grandes alterações, sob os impactos da "ideologia do gerencialismo", (RAICHELIS, 2018a) que emerge como estratégia de "governança" do Estado capitalista atual, caracterizada pelo tecnicismo, que busca levar os "imperativos, as premências e as lógicas das empresas privadas" para o âmbito do Estado, sob o argumento de que a "governança" privada é mais eficaz que a administração pública (cf. DARDOT; LAVAL, 2016). Cabe observar, que sob essas bases encontram-se processos de intensificação e precarização do trabalho profissional que "vão sendo incorporadas de forma sutil e gradativa [...] ganhando concretude no ritmo e na velocidade do trabalho, na polivalência e na multiatividade, nas cobranças de metas de produtividade, no maior volume da tarefas, no peso da responsabilidade" (RAICHELIS, 2018b, p. 59).

Outro aspecto a ser destacado em termos de demandas aos assistentes sociais, situa-se na área da produção de conhecimentos onde a profissão avançou na construção de,

[...] uma massa crítica de conhecimentos, contribuindo para a formação da cultura profissional - teórica, ética e ideopolítica - que se contrapôs e se contrapõe às iniciativas de construção da hegemonia das classes dominantes, em orgânica articulação, a partir dos finais dos anos 70 , com a esquerda marxista no Brasil (MOTA, 2017, p. 46-47).

Para Mota (2017, p. 42) nessa conjuntura,

[...] é da nossa competência profissional e intelectual politizar e analisar o crescimento dessas políticas, mostrando seus limites, e não apenas a importância de mantê-las, mas principalmente, a de ampliá-las, conquistando novos direitos e acessos a bens e serviços no âmbito do trabalho, da moradia, da mobilidade urbana, da segurança pública e da Seguridade Social.

Em síntese, é por essa inserção como trabalhadores, nas relações sociais capitalistas, no atual contexto de crise do capital, que os assistentes sociais constroem cotidianamente seu projeto e sua resistência, ao operacionalizar Políticas Sociais que focalizam e ameaçam o direito. Convivendo muito de perto com as atuais manifestações da Questão Social e suas resultantes econômicas, políticas e culturais, cujos impactos se revelam nos espaços institucionais em que atuam profissionalmente, os trabalhadores assistentes sociais enfrentam novas questões que evidenciam as diversas manifestações da desigualdade e da diversidade humana.

Nos diversos espaços profissionais, sob a condição de trabalhador assalariado, os assistentes sociais brasileiros administram as profundas transformações que ocorrem nas 
Políticas Sociais até mesmo medidas que apontam para sua extinção. Desvendar o processamento desse trabalho no contexto de sua forma neoliberal e sob o domínio do capital financeiro é enfrentar o desafio de operar a construção do direito em tempos adversos, apoiando e fortalecendo as lutas da "classe que vive do trabalho", da qual os assistentes sociais fazem parte. Direitos que sendo públicos têm a universalidade como perspectiva, envolvem interesses coletivos (interesses de uma classe social), tem visibilidade pública, transparência e exigem o controle social, a participação e a democratização e estão dramaticamente ameaçados.

\section{Considerações Finais}

O desafio frente ao quadro aqui brevemente apresentado no âmbito da luta pelo reconhecimento público e a construção dos direitos sociais da população com a qual é trabalhado é enorme, imensurável. E é nesse âmbito que deve-se localizar o significado do trabalho profissional, especialmente na gestão e operacionalização de políticas sociais: na disputa pelos sentidos da sociedade, na luta contra o desmanche de direitos cuja regulação vai passando para espaços do mundo privado; na construção de parâmetros capazes de deter a privatização do público, e a destruição da política, na perspectiva de construir a hegemonia das classes que vivem do trabalho em na sociedade. Isso a política social pode construir, deve construir.

Na realidade, não existe direito sem sua concreta realização e sem suas mediações, e a Política Social é sem dúvida mediação fundamental nesse sentido. E, se a política opera de forma descontínua, incompleta, seletiva e não democrática, passa a ter outro significado: controle e enquadramento dos pobres.

Em síntese, de modo geral a profissão é interpelada e desafiada pela necessidade de construir direitos e outras mediações políticas e ideológicas expressas sobretudo por ações de resistência e de alianças estratégicas no jogo da política em suas múltiplas dimensões, por dentro dos espaços institucionais e especialmente no contexto das lutas sociais. Seja no tempo miúdo do cotidiano, por dentro dos espaços institucionais onde atuase, politizando as iniciativas, buscando novas práticas, espaços a ocupar como conselhos e fóruns, considerando as variadas lutas e propostas de resistência. Seja no apoio às resistências cotidianas das classes subalternas em suas lutas na sociedade, expressando que profissionalmente caminham junto aos usuários. 
Vive-se um momento histórico, onde não existe possibilidade concreta das políticas sociais, particularmente aquelas voltadas à minimização da pobreza, não serem inflexionadas pelas contrarreformas em curso. Não existe possibilidade histórica, por exemplo, dos Programas de Transferência de Renda, do SUS, do SUAS, da Educação em todos os seus níveis, dos programas habitacionais, entre outros, deixarem de sofrer os impactos da Proposta de Emenda Constitucional - PEC - do congelamento dos gastos, como não existe possibilidade do campo dos serviços sociais deixar de sofrer as consequências da lei de terceirização irrestrita, e da classe que vive do trabalho não sofrer os impactos da reforma trabalhista e da reforma da previdência.

\begin{abstract}
Na verdade, o que está em jogo nessa conjuntura política é a ruptura do pacto que se construiu em torno da Constituição Federal de 1988, com base na ideia que ela não cabe no orçamento, que os direitos sociais oneram demais o fundo público, disseminando-se a 'cultura da crise' como responsabilidade de toda a sociedade. 0 processo golpista está em pleno curso e não é possível prever o seu desfecho. Cabe, no entanto, um chamamento à unidade política das forças progressistas em defesa da democracia e dos direitos sociais (RAICHELIS; YAZBEK, 2018, p.47).
\end{abstract}

\title{
Referências
}

ANTUNES, R. A nova morfologia do trabalho e suas principais tendências. In: ANTUNES, R. (org.). Riqueza e miséria do trabalho no Brasil II. São Paulo: Boitempo Editorial, 2013. Cap. 1.

ANTUNES, R. Os sentidos do trabalho: ensaio sobre a afirmação e a negação do trabalho. São Paulo: Boitempo Editorial, 1999.

ANTUNES, R. Prefácio. In: RAICHELIS, R.; VICENTE, D.; ALBUQUERQUE, V. (org.). A nova morfologia do trabalho no Serviço Social. São Paulo: Cortez, 2018. p. 9-14.

DARDOT, P.; LAVAL, C. A nova razão do mundo: ensaio sobre a sociedade neoliberal. São Paulo: Boitempo Editorial, 2016.

DOWBOR, L. A era do capital improdutivo. São Paulo: Autonomia Literária, 2017.

FILGUEIRAS, Luiz; GONÇALVES, Reinaldo. Desestruturação do trabalho e política social. In: PEREIRA, Potyara Amazoneida et al. (Orgs.). Política social, trabalho e democracia em questão. Programa de Pós-Graduação em Política Social, Universidade de Brasília, Brasília, 2009IAMAMOTO, M. V. Serviço Social em tempo de capital fetiche: capital financeiro, trabalho e questão social. São Paulo: Cortez, 2011.

IAMAMOTO, M. V. Serviço Social, "questão social" e trabalho em tempo de capital fetiche. In: RAICHELIS, R.; VICENTE, D.; ALBUQUERQUE, V. (org.). A nova morfologia do trabalho no Serviço Social. São Paulo: Cortez, 2018. p. 66-87.

IAMAMOTO, M. V.; CARVALHO, R. Relações sociais e serviço social no Brasil: esboço de uma interpretação histórico/metodológica. 10. ed. São Paulo: Cortez, 1995. 
IVO, A. B. L. A reconversão da questão social e a retórica da pobreza nos anos de 1990. In: DEAN, H.; CLIMADAMORE, A.; SIQUEIRA, J. (org.). A pobreza do Estado: reconsiderando o papel do Estado na luta contra a pobreza global. Buenos Aires: Clacso, 2006. p. 61-85.

MARQUES, R. M. O capitalismo financeiro e as políticas sociais: a nova face da contemporaneidade. In: RAICHELIS, R.; VICENTE, D.; ALBUQUERQUE, V. (org.). A nova morfologia do trabalho no Serviço Social. São Paulo: Cortez, 2018. p. 108-125.

MARQUES, R. M. O lugar das políticas sociais no capitalismo contemporâneo. Argumentum, Vitória, v. 7, n. 2, p. 7-21, jul./dez. 2015.

MOTA, A. E. 80 anos do Serviço Social brasileiro: conquistas históricas e desafios na atual conjuntura. Serviço Social e Sociedade, São Paulo, n. 128, p. 39-53, jan./abr. 2017.

OLIVEIRA, F. Crítica à razão dualista. O ornitorrinco. São Paulo: Boitempo Editorial, 2003.

OLIVEIRA, F. Uma biografia não autorizada. São Paulo: Boitempo, 2018.

RAICHELIS, R. Polêmicas teóricas na análise marxiana do trabalho no Serviço Social. Revista Em Pauta, Rio de Janeiro, v. 16, n. 41, p. 154-170, jan./jun. 2018a.

RAICHELIS, R. Serviço Social: trabalho e profissão na trama do capitalismo contemporâneo. In: RAICHELIS, R.; VICENTE, D.; ALBUQUERQUE, V. (org.). A nova morfologia do trabalho no Serviço Social. São Paulo: Cortez, 2018b. p. 25-65.

RAICHELIS, R.; YAZBEK, M. C. Estudo avaliativo da implementação do Sistema Único de Assistência Social: uma proposta de investigação em desenvolvimento. In: ENCONTRO NACIONAL DE PESQUISADORES EM SERVIÇO SOCIAL, 16., 2018, Vitória. Anais [...]. Vitória: UFES, 2018.

SINGER, A. O lulismo em crise: um quebra-cabeça do período Dilma (2011-2016). São Paulo: Companhia das Letras, 2018.

YAZBEK, M. C. Direitos sociais, políticas sociais e novos desafios para o Serviço Social. In: RONDON, E.; ARAÚJO, S. S.; ROCHA, S. (org.). Serviço Social, velhas e novas fronteiras. Rio de Janeiro: Autografia, 2017a.

YAZBEK, M. C. O significado sócio-histórico da profissão. In: CONSELHO FEDERAL DE SERVIÇO SOCIAL; ASSOCIAÇÃO BRASILEIRA DE ENSINO E PESQUISA EM SERVIÇO SOCIAL (org.). ServiçO Social: direitos sociais e competências profissionais. Brasília: CFESS: ABEPSS, 2009.

YAZBEK, M. C. Pobreza e exclusão social: expressões da questão social no Brasil. Temporalis: Revista da ABEPSS, Brasília, v. 2, n. 3, p. 33-40, jan./jun. 2001.

YAZBEK, M. C. Prefácio. In: SILVA, M. L. O. (org.). Serviço Social no Brasil: história de resistências e de ruptura com o conservadorismo. São Paulo: Cortez, 2017b. 